\title{
PERENCANAAN JARINGAN IRIGASI AIR TANAH DI DESA BUIN BARU KECAMATAN BUER KABUPATEN SUMBAWA
}

\author{
ZULKARNAEN ${ }^{1}$, ADY PURNAMA ${ }^{2}$, ISMAIL AMIN ${ }^{3}$ \\ Dosen Program Studi Teknik Sipil Fakultas Teknik Universitas Samawa Sumbawa Besar ${ }^{1,2}$ \\ Mahasiswa Program Studi Teknik Sipil Fakultas Teknik Universitas Samawa Sumbawa Besar ${ }^{3}$
}

\begin{abstract}
ABSTRAK
Desa Buin Baru merupakan salah satu desa yang terletak di Kecamatan Buer Kabupaten Sumbawa. Dengan kondisi wilayah yang berada di dekat pantai membuat terbatasnya ketersediaan air permukaan dan berdasarkan survei yang dilakukan menyatakan sulitnya mendapatkan air sehingga petanihanya mengandalkan air hujan, maka diupayakan dengan memanfaatkan air tanah dengan cara membuat sumur pompa, Dimana potensi lahan pertanian cukup besar. Untuk mengatasi hal tersebut, Balai Wilayah Sungai I membuat sumur produksi dengan melakukan pengeboran sumur dalam di desa BuinBaru. Tujuan dari studi ini adalah menghitung kebuthan air irigasi dan merencanakan jaringairi gasi air tanah (JIAT) serta menghitung rencana anggaran biaya yang dibutuhkan untuk membangun jaringa nirigasi air tanah tersebut.

Debit sumur yang dihasilkan oleh sumur adalah 9,66 I/dt, Pola tanam yang digunakan adalah padi - palawija. Kebutuhan air irigasi adalah 1,23 l/dt/ha dan luas wilayah layanan sebesar 9,6 ha. Perencanaan jaringan irigasi air tanah digunakan system pemberian air secara rotasi dimana dibagi menjadi 3 blok. Pompa yang digunakan berkapasitas 16,60 l/dt dan maksimum head $40 \mathrm{~m}$ dengan mesin diesel 4 engine stroke. Total anggaran yang direncanakan untuk perencanaan jaringan irigasi air tanah inia dalah Rp924.490.000,00.
\end{abstract}

Kata Kunci : JaringanIrigasi Air Tanah, Kebutuhan Air Irigasi

\section{PENDAHULUAN}

Menurut Matthews, 2005 Air adalah zat atau material atau unsur penting bagi semua bentuk kehidupan yang diketahui sampai saat ini di bumi, tetapi tidak di planet lain dalam sistem tata surya dan menutupi hampir $71 \%$ permukaan bumi. (Kodoatie, 2012:35).

Menurut Parker, 2007 air adalah Ujudnya bisa berupa cairan, es (padat) dan uap/gas. Dengan kata lain karena adanya air, maka bumi merupakan satu-satunya planet dalam tata surya yang memiliki kehidupan. (Kodoatie, 2012:35).

Air merupakan sumber daya alam yang sangat penting bagi kehidupan manusia, oleh karena itu sudah selayaknya sumber daya tersebut harus dimanfaatkan dan dikendalikan semaksimal mungkin sehingga potensi yang terkandung di dalamnya berguna bagi kehidupan. Sumber daya air dapat berasal dari air hujan, air permukaan (sungai, danau), mata air, dan air tanah. Sedangkan pemanfaatan sumber daya air umumnya antara lain untuk keperluan penyediaan air bersih, air minum (domestik), pertanian (irigasi), pariwisata serta industri dan lain - lain.

Air juga merupakan bagian penting dari sumber daya alam yang mempunyai karakteristik unik dibandingkan dengan sumber daya alam lainnya. Air bersifat sumber daya yang terbarukan dan dinamis. Artinya sumber utama air yang berupa hujan akan selalu datang sesuai dengan waktu atau musimnya sepanjang tahun. (Kodoatie, 2012:35).

Dalam mencapai ketahanan dan kemandirian pangan melalui peningkatan produksi pangan khususnya beras, pemanfaatan air tanah dapat digunakan sebagai air irigasi di daerah-daerah yang kekurangan air, dimana air permukaan tidak memadai atau tidak ada sama sekali serta daerah tersebut memiliki potensi pertanian. 
Pemanfaatan air tanah dalam haruslah sesuai daya dukung akuifer setempat yang penggunaannya diatur dengan perangkat kebijakan yaitu Undang-undang Sumber Daya Air No. 7 Tahun 2004, Peraturan Pemerintah No. 43 Tahun 2008 tentang Air Tanah serta Peraturan Daerah.

Menurut Peraturan Pemerintah Nomor 20 Tahun 2006, Bab I, pasal 1 ayat (16), Jaringan Irigasi Air Tanah (JIAT) adalah jaringan irigasi yang airnya berasaldari air tanah, mulai dari sumur dan instalasi pompa sampai dengan saluran irigasi air tanah termasuk bangunan didalamnya. Sistem pengairan jaringan irigasi air tanah ini menggunakan media saluran tertutup/perpipaan beserta aksesoris perpipaan.

KecamatanBuer adalah salah satu kecamatan yang ada di Kabupaten Sumbawa dengan luas wilayah $13.701 \mathrm{Km}^{2}$. Kecamatan Buer terdiri dari 6 Desa, 20 Dusun, 34 Rukun Warga, 82 Rukun Tetangga, dan dihuni oleh 3.726 Rumah Tangga. Curah hujan tertinggi terjadi pada bulan Januari 2014 yaitu mencapai $150 \mathrm{~mm}$ dengan jumlah hari hujan mencapai 14 hari, sementara pada bulan September dan Oktober sama sekali tidak terjadi hujan.(BPS Sumbawa:2015).

Desa Buin Baru merupakan salah satu desa yang terletak di Kecamatan Buer Kabupaten Sumbawa. Dengan kondisi wilayah yang berada di dekat pantai membuat terbatasnya ketersediaan air permukaan dan berdasarkan survei yang dilakukan menyatakan sulitnya mendapatkan air sehingga petani hanya mengandalkan air hujan, maka diupayakan dengan memanfaatkan air tanah dengan cara membuat sumur pompa,dimana potensi lahan pertanian cukup besar. Pemanfaatan air tanah dapat digunakan sebagai air irigasi pada daerah kekurangan air, dimana air permukaan tidak memadai atau tidak ada sama sekali sedangkan daerah tersebut memiliki potensi pertanian. Pembangunan jaringan irigasi air tanah ini merupakan upaya untuk membantu petani lokal yang tinggal atau mempunyai areal pertanian di daerah yang tidak tercakup dalam sistem irigasi permukaan atau pertanian lahan kering/ hotikultura yang hanya bisa melakukan kegiatan pengolahan pertanian satu kali dalam setahun.
Dari permasalahan diatas maka perlu kiranya dilakukan studi yang mengkaji mengenai "Perencanaan Jaringan Irigasi Air Tanah (JIAT) di Desa Buin Baru Kecamatan Buer Kabupaten Sumbawa".

\section{METODE PENELITIAN}

Kecamatan Buer merupakan satu dari 24 Kecamatan yang ada di Kabupaten Sumbawa yang terletak di Pulau Sumbawa bagian Barat, dengan batas sebagai berikut :

$\begin{array}{ll}\text { Utara } & \text { : Selat Alas } \\ \text { Selatan } & \text { : Kecamatan Batulanteh } \\ \text { Timur } & \text { : Kecamatan Utan } \\ \text { Barat } & \text { : Kecamatan Alas }\end{array}$

Desa Buin Baru memiliki luas wilayah sebesar $4.628 \mathrm{Ha}$, Sedangkan untuk jumlah penduduk Desa Buin Baru adalah 2.188 Jiwa. (http://www.sumbawakab.go.id/profil_Kec.ph p?idNya=7).

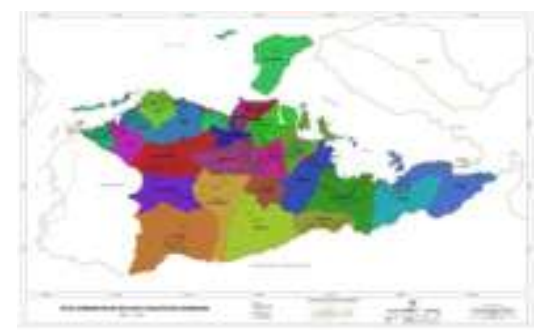

Gambar 1. Peta Administrasi

Wilayah Kab. Sumbawa (Bappeda, SDA

Spasial Kab. Sumbawa : 2014)

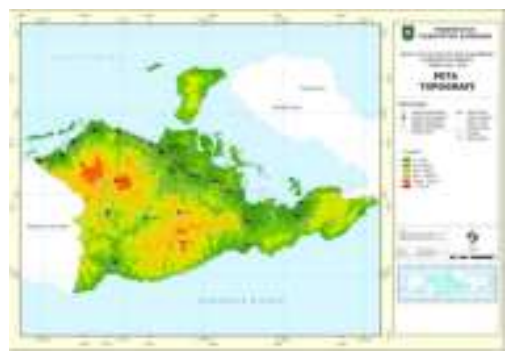

Gambar 2. Peta Topografi

Kab. Sumbawa (Bappeda, Sumber Daya Alam Spasial Kab. Sumbawa : 2014)

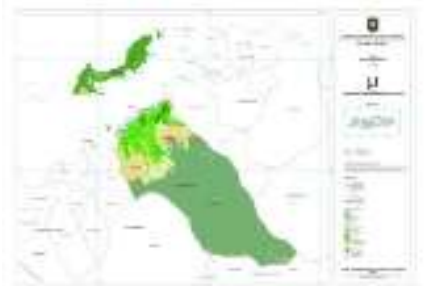

Gambar 3. Peta Administrasi

Kec. Utan (Bappeda Sumbawa : 1999) 


\section{Lokasi Penelitian}

Lokasi penelitian berada di ketinggian $\pm 16 \mathrm{Mdpl}$, pada koordinat $8^{\circ} 27^{\prime} 3.02^{\prime \prime} \mathrm{S}$, $117^{\circ} 2^{\prime} 57.40^{\prime \prime}$. Terletak di Desa Buin Baru Kecamatan Buer Kabupaten Sumbawa. Secara geografis berada di pesisir pantai pulau Sumbawa dengan wilayah cukup landai. Sumur pompa direncanakan akan melayani kebuutuhan air irigasi pada sawah seluas 9,6 $\mathrm{Ha}$, dimana debit sumur pompa pada lokasi penelitian didapat debit sebesar $9,66 \mathrm{Lt} / \mathrm{dt}$.

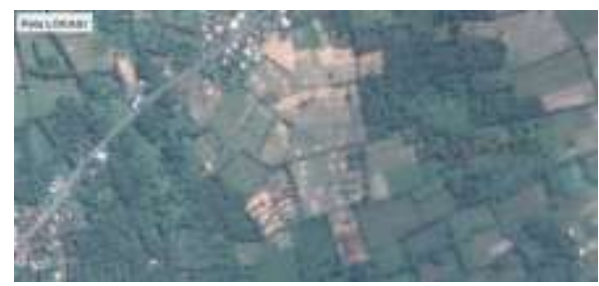

Gambar 4. Lokasi Penelitian

(Google Earth : 2016)

\section{Pengumpulan Data}

Adapun sistematika yang dilakukan dalam pengumpulan data sebagai berikut:

a) Mengumpulkan beberapa literatur dari buku-buku, skripsi, jurnal, makalah dan sumber lain yang berkenaan dengan pembahasan.

b) Mengumpulkan data - data yang diperlukan yaitu data primer dan data sekunder. Data primer disini tidak ada dikarenakan semua data sudah ada didapat dari instansi terkait sedangkan Data sekunder merupakan data yang didapat dari instansi terkait, lembaga masyarakat, dan pihak terkait yang berhubungan dengan penelitian ini. Data yang digunakan dapat dilihat dalam lampiran skripsi ini.

\section{Analisis Data}

Setelah dilakukan pengumpulan data, maka data-data yang di peroleh dianalisa dengan yang meliputi:

1) Pengolahan Data Curah Hujan Pengolahan data curah hujan diperoleh dengan menggunakan persamaan 2-1.

2) Curah Hujan Efektif

Curah hujan efektif diperoleh dengan menggunakan persamaan 2-2 dan 2-3.

3) Evapontranspirasi
Evapontranspirasi diperoleh dengan menggunakan persamaan 2-4 dan 25.

4) Penggunaan Air Konsumtif Penggunaan Air Konsumtif diperoleh dengan menggunakan persamaan 2-6.

5) Kebutuhan Air Untuk Penyiapan Lahan Kebutuhan Air Untuk Penyiapan Lahan diperoleh dengan menggunakan persamaan 2-7, 2-8, dan 2-9.

6) Kebutuhan Air Irigasi Kebutuhan Air Irigasi diperoleh dengan menggunakan metode PU.

7) Analisa Neraca Air Analisa Neraca Air diperoleh dengan membandingkan ketersediaan air dengan kebutuhan air untuk suatu tempat.

8) Perhitungan Perpipaan

Perhitungan Perpipaan diperoleh dengan menggunakan persamaan 2-10 s/d 2.14.

9) Perhitungan Rencana Anggaran Biaya Perhitungan Rencana Anggaran Biaya diperoleh dari perhitungan biaya yang dihitung berdasarkan kebutuhan pembangunan jaringan irigasi air tanah. 
Jurnal SAIJ $\mathcal{N}$ EK U UNSA, Volume 2, Nomor 1, Februari 2017

Bagan Alir Penelitian

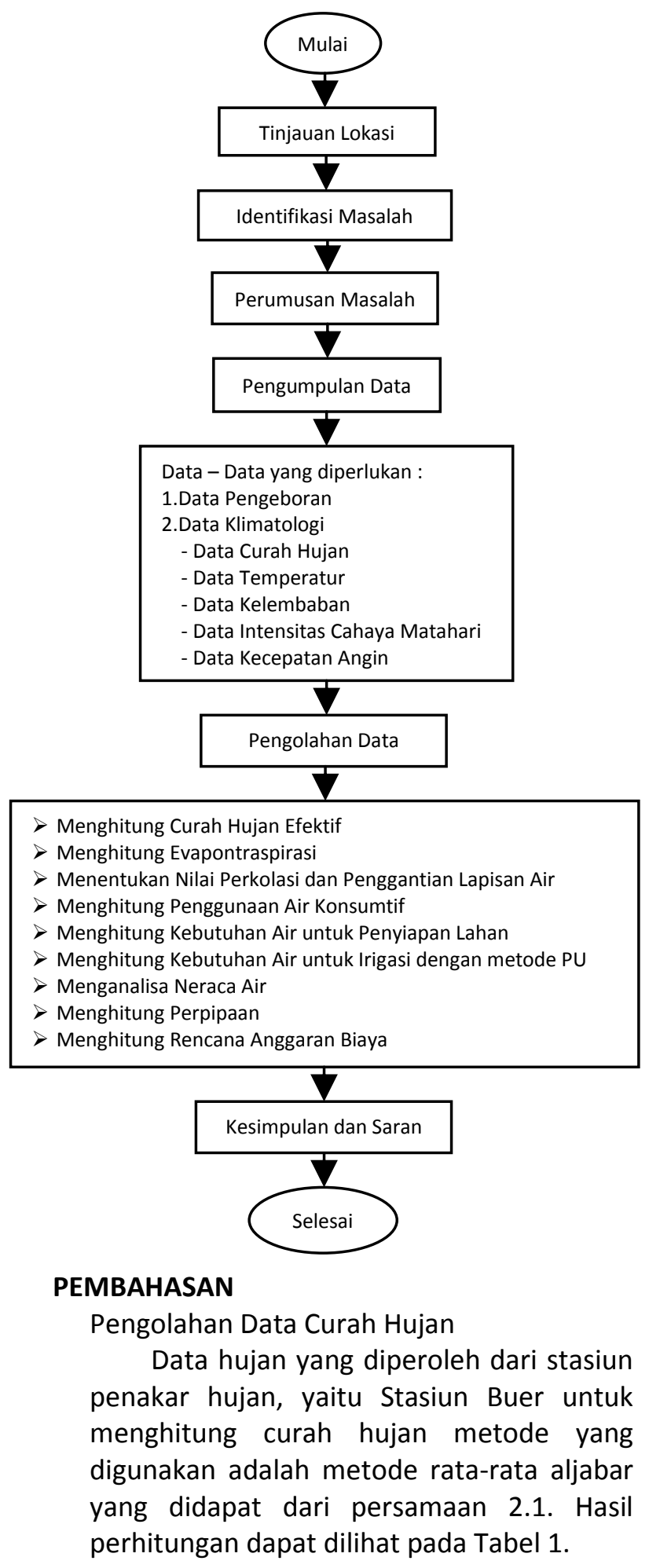

Tabel 1. Curah Hujan Rata-Rata Tahunan Stasiun Buer

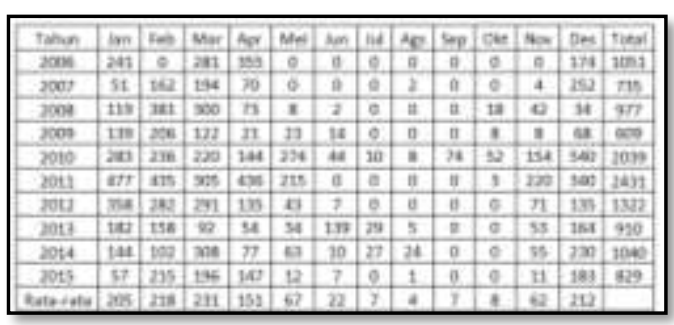

Dari hasil perhitungan di atas, terlihat bahwa curah hujan maksimum ratarata terjadi di bulan Maret sebesar 231 $\mathrm{mm}$ dan terendah terjadi di bulan Agustus sebesar $4 \mathrm{~mm}$.

\section{Curah Hujan Efektif}

Data Hujan yang dipakai untuk perencanaan ini menggunakan data pengamatan selama 10 tahun. Data hujan yang dipakai untuk menentukan curah hujan efektif adalah data curah hujan di Stasiun Buer. Untuk menghitung curah hujan efektif diperoleh dengan menggunakan data curah hujan bulanan dari yang terbesar hingga terkecil dengan persamaan 2.14 dan 2.15. Besarnya probilitas diperoleh dari nomor urut sampel yang telah diurutkan dari yang terbesar hingga terkecil.

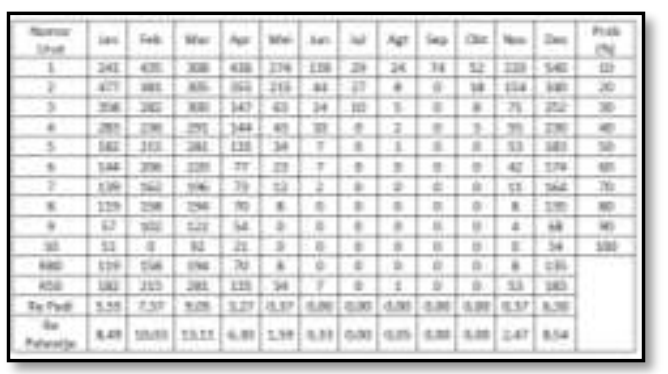

Tabel 2. Curah Hujan Efektif

Analisa pada tabel 2 diperoleh dengan menggunakan perhitungan sebagai berikut:

a) Untuk Re Tanaman Padi, contoh perhitungan dipakai $\mathrm{R}-80=119$ untuk bulan Januari.

$$
\begin{aligned}
& \mathrm{Re}=0,7 \times \mathrm{R}-80 \\
& \mathrm{Re}=0,7 \times 119 \\
& \mathrm{Re}=5,55 \mathrm{~mm} / \mathrm{hr}
\end{aligned}
$$

b) Untuk Re Tanaman Palawija, contoh perhitungan dipakai $\mathrm{R}-50=182$ untuk bulan Januari. 


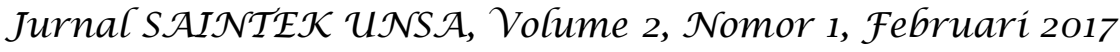

$$
\begin{aligned}
& \text { c) } \operatorname{Re}=0,7 \times \mathrm{R}-50 \\
& \operatorname{Re}=0,7 \times 182 \\
& \operatorname{Re}=8,49 \mathrm{~mm} / \mathrm{hr} \\
& \text { Evapontranspirasi }
\end{aligned}
$$

\section{Evapontranspirasi}

Besarnya evapotranspirasi potensial dapat dihitung dengan menggunakan Metode Penman yang sudah dimodifikasi guna perhitungan di daerah Indonesia. Adapun persamaan yang digunakan dapat dilihat dipersamaan 2.2 dan 2.3. Untuk menghitung besarnya evapontraspirasi, dibutuhkan data-data klimatologi yang meliputi temperatur, kelembaban relatif, lama penyinaran matahari, dan kecepatan angin.

Tabel 3. Perhitungan

Evapontranspirasi

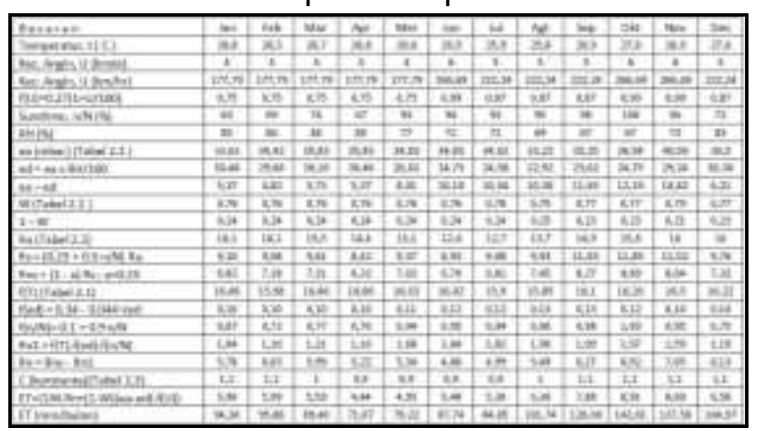

Analisa pada tabel 3 diperoleh dengan menggunakan persamaan 2.2 dan 2.3 dengan menggunakan persamaan diatas dapat dihitung evapotranspirasi :

Sebagai contoh pada bulan januari, dari lampiran data klimatologi yaitu :

a) Temperatur udara $(\mathrm{t})=26,8{ }^{\circ} \mathrm{C}$

b) Kecepatan angin (U) $=177,79$ $\mathrm{Km} / \mathrm{hari}$

c) Penyinaran matahari $\mathrm{n} / \mathrm{N}=63 \%$

d) Kelembaban udara $(\mathrm{RH})=85 \%$

1) Menghitung radiasi yang dating (Rs):

Rs $=(0.25+0.5 \mathrm{n} / \mathrm{N})$ Ra Daerah irigasi

Buer berada pada posisi $8^{\circ} 27^{\prime} 3.02$ "SLintang Selatan (LS) dan $117^{\circ} 2^{\prime} 57.40^{\prime \prime} T$ Bujur Timur (BT) maka Ra:

Posisi Lintang $=8 x\left(\frac{27}{60}\right)=8,45$

Dari tabel 2 didapat Ra $8,45^{\circ} \mathrm{LU}=16,1$

(interpolasi)

Jadi Rs $=\{0,25+0,5 \times(0,337)\} \times 16,1=$

$9,10 \mathrm{~mm} /$ hari

2) Menghitung Tekanan Uap nyata ed $=\mathrm{RH} \times$ ea

dari tabel 2.1 didapat Sta $26,8^{\circ} \mathrm{C}$, ea = $35,83 \mathrm{mbar}$

ed $=85 / 100 \times 35,83=30,46 \mathrm{mbar}$

3) Menghitung Radiasi netto gelombang pendek

Rns $=$ Rs . $(1-\alpha)$, dimana $\alpha=0,25$

$$
=9,10 \times(1-0,25)
$$$$
=6,82
$$

4) Menghitung fungsi tekanan uap nyata $f(\text { ed) }=0,33-0,044 \text {. (ed })^{0,5}$

$=0,33-0,044 \cdot(30,46)^{0,5}$

$=0,33-0,044 \cdot(5,52)$

$=0,10$

5) Menghitung fungsi rasio lama

penyinaran

$$
\begin{aligned}
\mathrm{f}(\mathrm{n} / \mathrm{N}) & =0,1+0,9 \mathrm{n} / \mathrm{N} \\
& =0,1+0,9(0,63) \\
& =0,67
\end{aligned}
$$

6) Menghitung Radiasi netto gelombang panjang

$R n l=f(T) \cdot f(e d) \cdot f(n / N)$

didapat Sta $26,8{ }^{\circ} \mathrm{C}, f(T)=16,1$

(interpolasi)

$\mathrm{Rn} 1=16,1 \times 0,10 \times 0,67=1,04$

7) Menghitung Radiasi netto

$$
\begin{aligned}
& \text { Rn }=\text { Rns }- \text { Rnl } \\
& =6,82-1,04 \\
& =5,78
\end{aligned}
$$

8) Menghitung Evapotranspirasi (Eto) $E T o=C \cdot[W \cdot R n+(1-W) \cdot f(U) \cdot($ ea-ed) $]$ Dari tabel 2.3 didapatAngka koreksi penmann c (konstanta) $=1,1$ Dari tabel didapat Sta $26,8^{\circ} \mathrm{C}, \mathrm{W}=0,76$ Eto $=1,1[0,76 \times 3,91+(1-0,76) \times(0,28)$ $\mathrm{x}(6,32)]$

$=5,90 \mathrm{~mm} /$ hari

Eto bulanan $=5,90 \times 16=94,36$ $\mathrm{mm} /$ setengah bulan. 


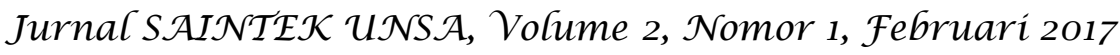

Tabel 4. Rekapitulasi

Evapontranspirasi

\begin{tabular}{|c|c|r|r|}
\hline \multirow{2}{*}{ No } & \multirow{2}{*}{ Bulan } & \multicolumn{2}{|c|}{ Evapontranspirasi } \\
\cline { 3 - 4 } & & (mm/hari) & (mm/bulan) \\
\hline 1 & Jan & 5,90 & 94,36 \\
\hline 2 & Feb & 5,99 & 95,86 \\
\hline 3 & Mar & 5,99 & 89,40 \\
\hline 4 & Apr & 4,44 & 71,07 \\
\hline 5 & Mei & 4,95 & 79,22 \\
\hline 6 & Jun & 5,48 & 87,74 \\
\hline 7 & Jul & 5,30 & 84,85 \\
\hline 8 & Agt & 6,36 & 101,74 \\
\hline 9 & Sep & 7,88 & 126,00 \\
\hline 10 & Okt & 8,91 & 142,61 \\
\hline 11 & Nov & 8,60 & 137,56 \\
\hline 12 & Des & 6,56 & 104,97 \\
\hline
\end{tabular}

\section{Perkolasi}

Laju perkolasi sangat bergantung pada sifat-sifat tanah. Untuk wilayah Nusa Tenggara Barat, perkolasi yang dipakai sebesar $2 \mathrm{~mm} /$ hari. (Direktorat Jenderal Pengairan).

\section{Penggantian Lapisan Air}

Penggantian lapisan air dilakukan penggantian sebanyak 2 kali, masingmasing $50 \mathrm{~mm}$ (atau $3,3 \mathrm{~mm} / \mathrm{hr}$ selama setengah bulan) selama satu bulan dan dua bulan setelah transplantasi. (Direktorat Jenderal Pengairan).

\section{Penggunaan Air Konsumtif}

Penggunaan air konsumtif dapat dihitung dengan persamaan 2.3. berikut merupakan hasil perhitungan kebutuhan penggunaan air konsumtif .

Tabel 5. Penggunaan Air Konsumtif

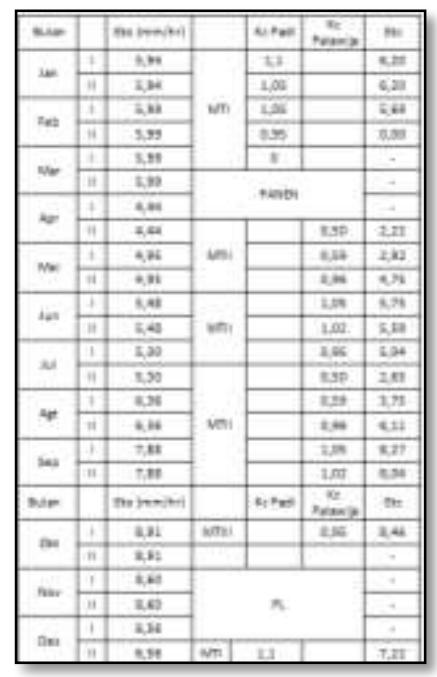

Contoh perhitungan pada bulan januari periode I adalah sebagai berikut :

$$
\begin{array}{ll}
\mathrm{ET}_{\mathrm{C}} & =\mathrm{K}_{\mathrm{C}} \times \mathrm{ETo} \\
\mathrm{ETc} & =1,1
\end{array}
$$

(Koefisien Tanaman Padi) x 5,94 (ETo Bulan Januari)

\section{$\mathrm{ETc}=6,20 \mathrm{~mm} / \mathrm{hr}$}

Dari Tabel 5 dapat dilihat penggunaan air konsumtif dimana MTI dimulai setelah penyiapan lahan yaitu pada bulan Desember. Penggunaan air konsumtif pada MTIterbesar terjadi pada bulan Desember yaitu $7,22 \mathrm{~mm} / \mathrm{hr}$. Untuk MTII penggunaan air konsumtif terbesar terjadi pada bulan Juni yaitu $5,75 \mathrm{~mm} / \mathrm{hr}$ sedangkan untuk MTIII penggunaan air konsumtif terbesar terjadi pada bulan Oktober yaitu 9,09 $\mathrm{mm} / \mathrm{hr}$.

\section{Kebutuhan Air Untuk Penyiapan Lahan}

Berikut ini adalah hasil analisis kebutuhan air untuk penyiapan lahan dari persamaan 2.10 sebagai berikut.

Tabel 6. Kebutuhan

Air untuk Penyiapan Lahan

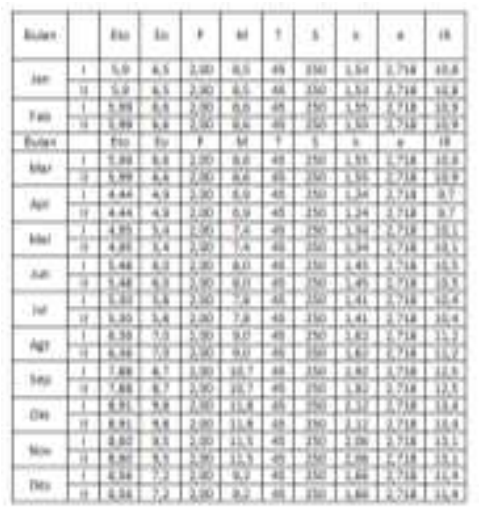

Contoh perhitungan kebutuhan air penyiapan lahan diambil pada bulan januari periode I sebagai berikut :

$$
\begin{aligned}
& I R=M \times \frac{\mathrm{e}^{\mathrm{k}}}{\left(\mathrm{e}^{\mathrm{k}}-1\right)} \\
& \mathrm{IR} \quad= 8,5 \times \frac{2,718^{1,53}}{\left(2,718^{1,53}-1\right)} \\
& \mathrm{IR} \quad=10,8 \mathrm{~mm} / \mathrm{hr} \\
& \text { Pada Tabel } 6 \text { menunjukkan }
\end{aligned}
$$
kebutuhan air untuk penyiapan lahan disetiap bulan dan dimana kebutuhan air untuk penyiapan lahan terbesar terjadi pada bulan Oktober yaitu 13,4 $\mathrm{mm} / \mathrm{hr}$ sedangkan kebutuhan air untuk 


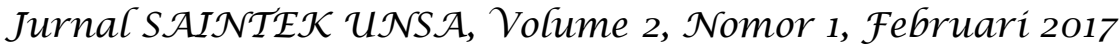

penyiapan lahan terkecil terjadi pada bulan April yaitu $9,7 \mathrm{~mm} / \mathrm{hr}$.

\section{Kebutuhan Air Irigasi}

Perhitungan kebutuhan air irigasi dilakukan dengan menggunakan metode standart perencanaan irigasi.Dimana pola tanam yang dipakai adalah Padi-Palawija-Palawija yang ditinjau dari kebiasaan petani setempat. Berikut adalah hasil perhitungan kebutuhan air irigasi pada tabel 7.

Tabel 7. Perhitungan

Kebutuhan Air Irigasi

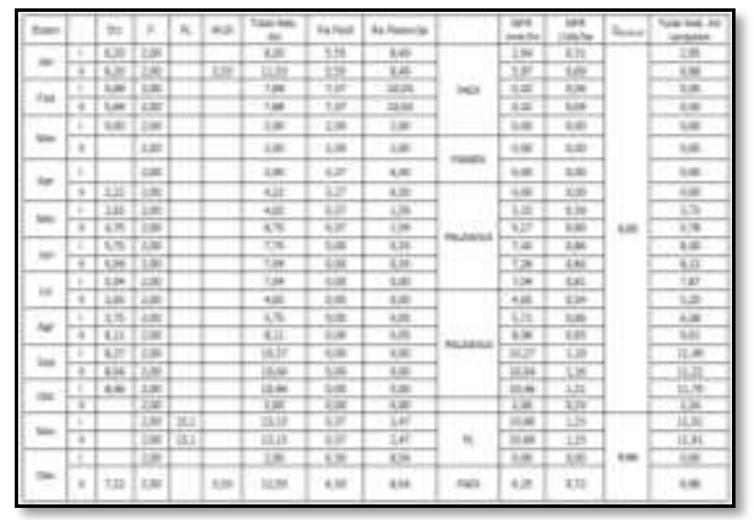

Contoh perhitungan kebutuhan air irigasi pada bulan januari periode I diperoleh sebagai berikut :

$\mathrm{NFR}=\mathrm{ETC}+\mathrm{P}+\mathrm{IR}+\mathrm{WLR}-\mathrm{Re}$

$\mathrm{NFR}=6,20+2,00+0,00+0,00-5,55$

$\mathrm{NFR}=2,64 \mathrm{~mm} / \mathrm{hr}$

$\mathrm{NFR}=2,64 \times 8,64$

$\mathrm{NFR}=0,31 \mathrm{l} / \mathrm{dt} / \mathrm{ha}$

$N F R=0,31 \times 9,66$ (luas areal rencana)

$\mathrm{NFR}=2,95 \mathrm{l} / \mathrm{dt} / \mathrm{ha}$

Dari tabel dapat disimpulkan kebutuhan air irigasi terbesar untuk MTI terjadi pada bulan Desember periode II adalah 6,98 I/dtk/ha, untuk MTII kebutuhan air irigasi terbesar terjadi pada bulan Juni yaitu 8,30 I/dtk/ha sedangkan untuk MTIII kebutuhan air irigasi terbesar terjadi pada bulan Oktober yaitu 11,70 l/dtk/ha.

\section{Analisa Neraca Air}

Analisa neraca air dilakukan untuk melihat apakah debit sumur cukup untuk memenuhi kebutuhan air irigasi.
Dari data diketahui debit sumur sebesar 9,66 l/dtk dan luas areal irigasi adalah 9,66 ha diasumsikan $1 \mathrm{l} / \mathrm{dt}=1$ ha petani. Berikut adalah grafik analisa neraca air untuk perencanaan jaringan irigasi air tanah.

Gambar 5. Grafik Analisa Neraca Air

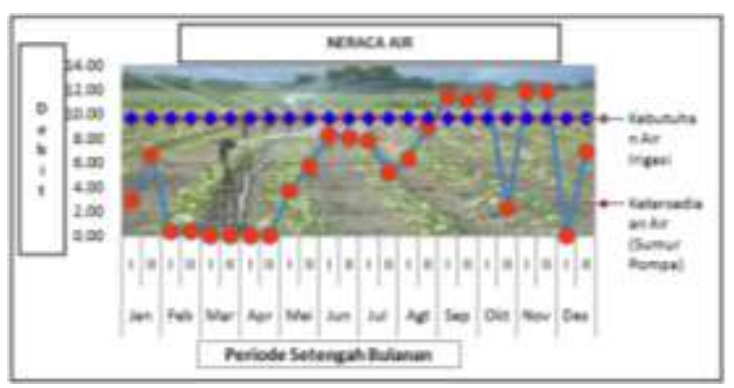

(Sumber : Pengolahan Data)

Dari grafik didapat kebutuhan air irigasi tertinggi terjadi pada masapenyiapan lahan yaitu bulan November. Sedangkan kebutuhan irigasi terendah terjadi pada MTI yaitu bulan maret saat masa tanam padi. Sehingga ditarik kesimpulan untuk masa tanam dengan pola tanam padipalawija-palawija dapat dilakukan dengan mengunakan metode pemberian secara rotasi agar pemberian air merata.

Pada perencanaan ini daerah irigasi dibagi 3 blok untuk pemerataan air sehingga semua lahan dapat terairi dan menjaga kualitas pompa agar dapat bertahan lama. Waktu pengoperasiannya pompa direncanakan selama 10 jam dalam 1 hari, sehingga lama waktu pengoperasian adalah $7 \times 10=70$ jam. Air yang harus disediakan sebesar $1,23 \mathrm{l} / \mathrm{dt} / \mathrm{ha}$ dari tabel 7.

Banyaknya air yang dibutuhkan dalam tiap blok adalah :

Blok $1=\frac{2,55}{1,23}=2,073 \mathrm{l} / \mathrm{dt}$

Blok $2=\frac{3,06}{1,23}=2,488 \mathrm{l} / \mathrm{dt}$

Blok $3=\frac{3,98}{1,23}=3,326 \mathrm{l} / \mathrm{dt}$

Maka jumlah air yang dibutuhkan seluruh blok adalah $7,80 \mathrm{l} / \mathrm{dt}$.

Untuk menentukan pemberian air jamjaman dalam 7 hari :

$$
\text { Blok } 1=70 \times \frac{2,073}{7,80}=19 \mathrm{jam}
$$


Blok $2=70 x \frac{2,488}{7,80}=22 \mathrm{jam}$

Blok $3=70 x \frac{3,326}{7,80}=29 \mathrm{jam}$

Tabel 8. Pemberian air selama 10 jam dalam 1 hari

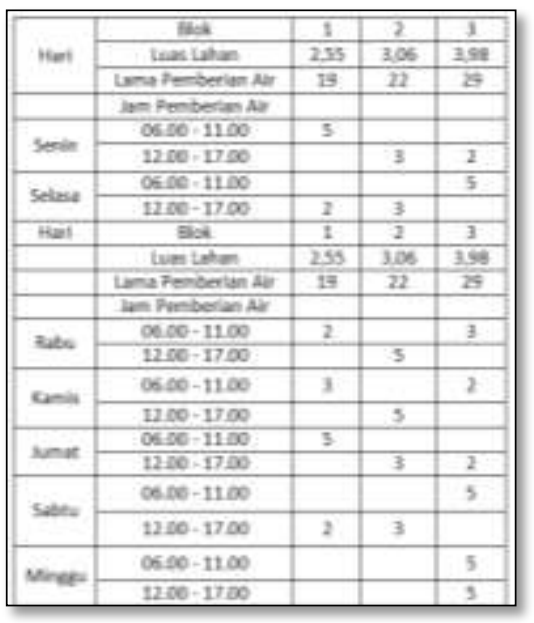

Pembagian kebutuhan air irgasi dibagi berdasarkan perencanaan jaringan irigasi yang dibuat berdasarkan data-data yang didapat. Dimana jaringan yang direncanakan dapat dilihat pada gambar 6 dan gambar 7 dibawah ini.

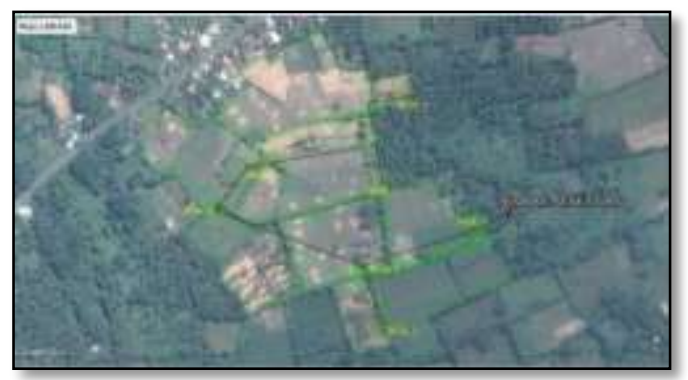

Gambar 6. Peta Rencana Jaringan Irigasi Air Tanah (Sumber : Pengolahan Data)

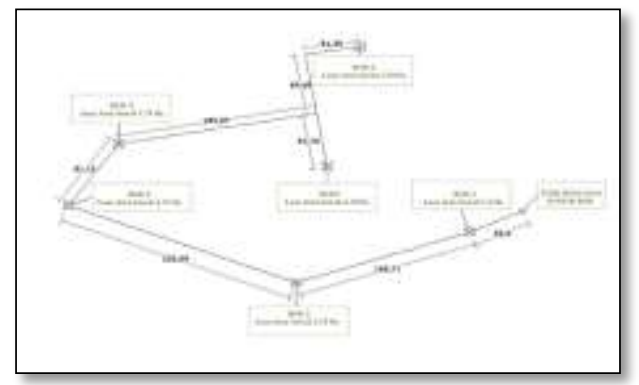

Gambar 7. Skema Jaringan Irigasi Perpipaan (Sumber : Pengolahan Data ) Perhitungan Perpipaan

Dalam merencanakan sistem jaringan irigasi perpipaan, aliran dalam pipa harus berada pada kondisi aliran turbulen. Untuk mengetahui kondisi aliran dalam pipa turbulen atau tidak, dapat dihitung dengan identifikasi bilangan Reynold menggunakan persamaan 2.8 .

$$
\operatorname{Re}=\frac{V \times D}{v}=\frac{1,2 \times 0,1016}{1,003 \times 10^{-6}}=120757, \operatorname{Re}>
$$

$4000 \rightarrow$ Aliran Turbulen.

Dari angka reynold diatas didapat bahwa aliran dalam pipa adalaha aliran turbulen.

Untuk perhitungan kehilangan tinggi tekan major dan kehilangan tinggi tekan minor serta total head pompa digunakan persamaan 2.9, persamaan 2.10, persamaan 2.11, dan persamaan 2.12, hasil dari perhitungan tersebut dapat dilihat dalam tabel dibawah ini.

Tabel 9. Kehilangan Tinggi Tekan (Head Loss) dan Total Head Pompa

\begin{tabular}{|c|c|c|c|c|c|c|c|}
\hline $\begin{array}{c}\text { No } \\
\text { titik }\end{array}$ & $\begin{array}{c}\text { Elevasi } \\
\text { (m) }\end{array}$ & $\begin{array}{l}\text { diameter } \\
\text { pipa (D) } \\
\text { (m) }\end{array}$ & $\begin{array}{l}\text { Luas } \\
\text { Lahan } \\
(\mathrm{Ha})\end{array}$ & $\begin{array}{l}\text { panjang } \\
\text { pipa (L) } \\
(\mathrm{m})\end{array}$ & $\begin{array}{l}h_{f} \\
(m)\end{array}$ & $\begin{array}{l}h_{l m} \\
(m)\end{array}$ & $\begin{array}{c}\mathrm{H} \\
(\mathrm{m})\end{array}$ \\
\hline BOK1 & 16 & 0,1016 & 1,2 & 53,92 & 0,695 & 0,116 & \multirow{7}{*}{17,21} \\
\hline BOK2 & 15 & 0,1016 & 1,35 & 168,71 & 2,175 & 0,116 & \\
\hline BOK3 & 16 & 0,1016 & 1,31 & 226,09 & 2,915 & 0,116 & \\
\hline BOK4 & 16 & 0,1016 & 1,75 & 81,13 & 1,046 & 0,116 & \\
\hline BOK5 & 16 & 0,1016 & 2,19 & 243,36 & 3,138 & 0,116 & \\
\hline BOK6 & 16 & 0,1016 & 1,79 & 116,04 & 1,496 & 0,261 & \\
\hline \multicolumn{3}{|c|}{ Total } & 9,6 & 889 & 11,47 & 0,841 & \\
\hline
\end{tabular}

Contoh perhitungan BOK1 pada tabel 9 dapat dilihat sebagai berikut :

$\mathrm{h}_{\mathrm{f}}=\mathrm{k} \times \mathrm{Q}^{1,85}$

$\mathrm{k}=\frac{10,654 \times \mathrm{L}}{\mathrm{C}_{\mathrm{hw}}^{1,85} \times \mathrm{D}^{4,87}}$

$k=\frac{10,654 \times 53,92}{150^{1,85} \times 0,1016^{4,87}}$

$\mathrm{k}=3714,68$

$h_{f}=3714,68 \times 0,00966^{1,85}$

$h_{f}=0,695 \mathrm{~m}$

$\mathrm{h}_{\mathrm{Lm}}=\mathrm{k} \times \frac{\mathrm{V}^{2}}{\mathrm{~g}}$

$h_{\text {Lm }}=0,8 \times \frac{1,2^{2}}{9,8}$

$\mathrm{h}_{\mathrm{Lm}}=0,116 \mathrm{~m}$

selanjutnya $h_{f}$ dan $h_{\llcorner m}$ ditotalkan lalu digunakan untuk menghitung $\mathrm{H}$ :

$\mathrm{H}=\mathrm{h}_{\mathrm{f}}+\mathrm{h}_{\mathrm{Im}}+\mathrm{Zb}+\frac{\mathrm{V}^{2}}{2 \times \mathrm{g}}$

$H=11,47+0,841+0+\frac{1,2^{2}}{2 \times 9,8}$

$\mathrm{H}=17,21 \mathrm{~m}$

\section{Rencana Anggaran Biaya}

Berikut adalah rencana anggaran

biaya untuk perencanaa jaringan irigasi air 
tanah yang dihitung dengan standar perencanaan PU.

Tabel 10. Rekapitulasi Rincian Anggaran Biaya (RAB)

\begin{tabular}{|c|c|c|}
\hline & Uraian Pekerjaan & $\begin{array}{l}\text { Jumlah Harga } \\
\text { (Rp) }\end{array}$ \\
\hline \multirow[t]{6}{*}{ I } & $\begin{array}{l}\text { Pekerjaan pembangunan jaringan irigasi air } \\
\text { tanah (JIAT) }\end{array}$ & $440.244 .915,70$ \\
\hline & A. Pembangunan Rumah Pompa & $42.765 .286,32$ \\
\hline & $\begin{array}{l}\text { B. Pekerjaan pembangunan pondasi } \\
\text { mesin dan pompa }\end{array}$ & $35.106 .288,16$ \\
\hline & C. Pekerjaan pembangunan riser pipe & $6.021 .736,19$ \\
\hline & D. Pekerjaan jaringan perpipaan & $297.539 .709,88$ \\
\hline & $\begin{array}{ll}\text { E. } & \text { Pekerjaan pagar keliling } \\
\end{array}$ & $58.811 .895,15$ \\
\hline \multirow[t]{9}{*}{ II } & Pekerjaan pengadaan mesin dan pompa & $400.200 .816,15$ \\
\hline & A. Pump bowl ass'y dan accessories & $222.400 .000,00$ \\
\hline & B. Fleksible Drive Shaft + Flange & $6.250 .000,00$ \\
\hline & C. Mesin Penggerak [Mesin Diesel] & $160.000 .000,00$ \\
\hline & $\begin{array}{l}\text { D. Pemasangan dan Uji Coba Serta } \\
\text { Pebongkaran Pompa dan Mesin Penggerak }\end{array}$ & $11.550 .816,15$ \\
\hline & Jumlah & $840.445 .731,86$ \\
\hline & PPN $10 \%$ & $84.044 .573,19$ \\
\hline & Grand Total & $924.490 .305,04$ \\
\hline & Dibulatkan & $924.490 .000,00$ \\
\hline \multicolumn{3}{|c|}{$\begin{array}{l}\text { Terbilang : Sembilan Ratus Dua Puluh Empat Juta Empat Ratus } \\
\text { Sembilan puluh Ribu Rupiah }\end{array}$} \\
\hline
\end{tabular}

Hasil rekapitulasi rencana anggaran biaya didapat dari perhitungan rincian rencana anggaran biaya yang ada pada lampiran IV, dibuat dengan menggunakan perhitungan yang sama dengan perhitungan dinas Pekerjaan Umum dalam membuat rencana anggaran biaya untuk sumur bor.

\section{Kesimpulan}

Berdasarkan rumusan masalah dan hasil kajian dari pembahasan, maka didapatkan kesimpulan sebagai berikut :

1) Perhitungan besarnya kebutuhan air irigasi dimana penyiapan lahan dimulai pada bulan November sehingga MTI dimulai bulan Desember, MTII dimulai bulan April dan MTIII dimulai bulan Juli mengikuti pola tanam petani didaerah kajian. Sehingga didapat NFR MTI tertinggi sebesar 6,98 $\mathrm{l} / \mathrm{dtk} / \mathrm{hr}$, MTII tertinggi sebesar $8,30 \mathrm{l} / \mathrm{dtk} / \mathrm{hr}$ dan MTIII tertinggi sebesar $11,91 \mathrm{l} / \mathrm{dtk} / \mathrm{hr}$.

2) Berdasarkan analisa neraca air direncanakan areal irigasi seluas 9,66 ha yang diasumsikan dari debit sumur pompa dimana $1 \mathrm{l} / \mathrm{dt}=1 \mathrm{ha}$, dimana kebutuhan air irigasi pada bulan tertentu melebihi debit sumur yang tersedia apabila dilakukan pemberian air secara terus-menerus, sehingga perencanaan jaringan irigasi air tanah didaerah kajian digunakan sistem rotasi atau giliran.

3) Pompa yang direncanakan adalah pompa turbin dengan kapasitas 16,60 l/dtk dan head maksimum $(\mathrm{H}) 40 \mathrm{~m}$ dengan mesin diesel 4 engine storke.

4) Rencana anggaran biaya untuk pembangunan jaringan irigasi air tanah sebesar Rp 924.490.000,00.

Saran

Berdasarkan hasil penelitian, maka peneliti menyarankan beberapa hal mengenai perencanaan jaringan irigasi air tanah :

1) Dalam skripsi ini belum diperhitungkan analisis ekonomi dari pembangunan jaringan irigasi air tanah sehingga untuk dapat dilaksanakan penelitian lanjutan.

2) Disarankan perhitungan perpipaan agar lebih akurat dilakukan dengan bantuan software.

3) Penelitian selanjutnya dapat membandingkan perencanaan jaringan irigasi air tanah sistem perpipaan dengan sistem tetes.

\section{DAFTAR PUSTAKA}

Anonim. 2007. Peraturan Menteri Pekerjaan Umum Nomor 32/PRT/M/2007, Tentang Operasi Dan Pemeliharaan Jaringan Irigasi. Kementerian Pekerjaan Umum . Jakarta.

Anonim. 2006. Peraturan Pemerintah No. 20 Tahun 2006, Tentang Irigasi. Deputi Menteri Sekretaris Negara Bidang Perundang-Undangan. Jakarta.

Anonim. 1998. Peraturan Pemerintah Tahun 1998, Tentang Irigasi. Kementerian Pekerjaan Umum. Jakarta.

Anonim. 2008. Peraturan Pemerintah Nomor 43 Tahun 2008, Tentang Pengelolaan Jaringan Irigasi. Kementerian Pekerjaan Umum. Jakarta.

Anonim. 2001. Peraturan Pemerintah Nomor 77 Tahun 2001, Tentang Irigasi. Kementerian Pekerjaan Umum. Jakarta.

Anonim. 2014. Laporan Kinerja Instansi Pemerintah 2014. Sumbawa: Pemda Sumbawa. 


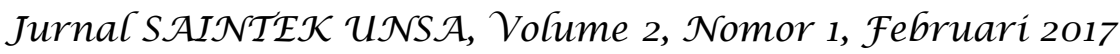

Anonim. 1986. Standar Perencanaan Irigasi,Kriteria Perencanaan Bagian Jaringan Irigasi KP-01. Bandung: C.V. Galang Persada.

Anonim. 2015. Statistik Daerah Kecamatan Utan 2015. Sumbawa: Badan Pusat Statistik.

Anonim. 2015. Profil Kecamatan Utan. http://www.sumbawakab.go.id/profil_Ke c.php?idNya=7. Diakses pada tanggal 2003-2016.

Anonim. 2016.

Irigasi. https://id.wikipedia.org/wiki/Irigasi\#. Diakses pada tanggal 20-03-2016.

Anonim. 2014. Pengelolaan Air Tanah Berdasarkan Peraturan Air Tanah. http://siat.bgl.esdm.go.id/?q=content/pe ngelolaan-air-tanah-berdasarkan-

peraturan-air-tanah. Diakses pada tanggal 20-03-2016.

Purnama, A, 2015. Konsentrasi Sedimen Suspensi pada Belokan $57^{\circ}$ Saluran Terbuka, Jurnal Unsa Progress. Vol.1, No.3, Oktober, Universitas Samawa, Sumbawa Besar.

Purnama, A., Badaruddin., dan Haris, A. 2016. PENGEMBANGAN SISTEM JARINGAN AIR BERSIH DENGAN METODE GRAVITASI DI DESA BATU TERING KECAMATAN MOYO HULU, Jurnal Saintek Unsa. Vol.1, No.2, September, Universitas Samawa, Sumbawa Besar.

Purnama, A., Nuraini, E, dan Saputri, D. E. 2016. STUDI KELAYAKAN SALURAN DRAINASE JALAN SULTAN KAHARUDDIN KM. 02 KABUPATEN SUMBAWA, Jurnal Saintek Unsa. Vol.1, No.1, Februari, Universitas Samawa, Sumbawa Besar. 